\title{
Study of Biological Properties of Effective Pesticides Destructor Pseudomonas Putida P2
}

\section{E V Vasnetsova1, E | Tikhomirova ${ }^{2}$, O Yu Ksenofontova ${ }^{1}$, and S Yu Efremova ${ }^{3}$}

${ }^{1}$ National Research Saratov State University named after N.G. Chernyshevskogo, Saratov, Russia

${ }^{2}$ Yuri Gagarin State Technical University of Saratov, Saratov, Russia

${ }^{3}$ Penza State Technological University, Penza, Russia

\section{Abstract}

A promising approach for remediation of contaminated soils is the use of biological products based on microorganisms-destructors. Of particular interest are the strains that can decompose several types of pollutants. Potential strains-destructors should be not only effective, but also adapted for certain soil and climatic conditions. In addition, when introducing a significant amount of biological agents into the ecosystem, the lack of toxicological and pathogenic effects on plants, animals and humans is particularly important. The object of the study is the destructor strain of sim-triazine herbicide of prometrin Pseudomonas putida P2. The study explores the ability of strain to use various pesticides as the only carbon source, the effect of bacterial culture on seed germination, biotesting of strain on toxicity using earthworms. Besides, the study presents the phytopathogenicity factors and enzymes causing bacteria invasiveness into animals and humans. The determination of dehydrogenase activity of prometrin destructor strain showes that this strain can also use active ingredients of pesticides malathion, $\mathrm{HCH}$ and 4,4-DDT as only sole carbon source. It is also established that the studied strain Pseudomonas putida P2 increases the germination of seeds of the variety Saratovskaya 70 and carrots of the variety Samson and does not possess pathogenicity factors. The strain biotesting on the earthworms revealed no acute toxicity of the culture. The analysis of data obtained from the model pollution shows that the introduction of the destructor of prometrinum Pseudomonas putida P2 into the soil can create favorable conditions for vital activity and reproduction of earthworms.

permits unrestricted use and redistribution provided that the original author and source are credited.

Keywords: soil remediation, biodestructor, Pseudomonas putida, pesticides, prometrin, 4,4-DDT, $\mathrm{HCH}$.

Selection and Peer-review under the responsibility of the AgroSMART 2019 Conference Committee.

\section{Introduction}

One of the urgent tasks of modern biotechnology is the creation of biologicals based on xenobiotic strains-destructors isolated from native microflora to solve a set of tasks related to rehabilitation of contaminated soils as a result of increasing man-made stress 
environment. They are mainly aimed at oil and oil products decomposition [4]. However, pesticides relate to significant global polluter of the Earth. Pesticides are widely used throughout the world and are constantly released into the environment. Pesticides can be accumulated in water, soil, plants, in living organisms and can even be transmitted through trophic chains, many of them have carcinogenic, mutagenic properties and cause disturbances in the vital activity of organisms.

Soils mostly degrade due to the intensive use of pesticides violations the norms and rules for their use, which leads to their accumulation in soils. The disposal sites for unused or prohibited chemicals are also of particular danger [6, 7]. Natural processes of soil self-purification are unable to cope with such volumes of pollution. A promising approach for remediation of contaminated soils is the use of biological products based on microorganisms [8, 9]. The use of biological products can reduce labor costs by 3--5 times and energy consumption by $50--100 \%$. It can increase the efficiency of cleaning 5 to 10 times. Due to the selective adaptation, the bacteria are able to multiply at high concentrations of pollutants and use the latter as sources of food and energy [10]. Today, it is an economically viable strategy and an environmentally friendly technology for the remediation of polluted ecotops [11].

Potential strains-destructors should not only be effective, but also adapted for certain soil and climatic conditions. In addition, when introducing a significant amount of biological agents into the ecosystem, their lack of toxicological and pathogenic effects on plants, animals and humans is particularly important. The absence of antagonistic relations between the introduced species and the autochthonous microbiological community is also very important. In this regard, the selection of strains-destructors for the use as a basis of biological product is a very crucial stage. In this regard, we studied the factors of pathogenicity and toxigenicity of strain-destructor of pesticide.

\section{Methods and Materials}

The object of the study was a strain-destructor of the sim-triazine herbicide of prometrin Pseudomonas putida P2 isolated from soil contaminated with pesticides. The State Standard Samples (GSO) of pesticides of prometrin, malathion, cypermethrin, foundation, lambda cyhalothrin, $\mathrm{HCH}$ and 4,4-DDT were used as chemicals (Table 1).

Identification of the ability of the strain to use various pesticides as the only carbon source was carried out by the presence of dehydrogenase. Since under the aerobic conditions the first stage of biodegradation of xenobiotics is oxidative metabolism reactions catalyzed by various oxidoreductases, the main of which are dehydrogenases, 
TABLE 1: Chemical classification of pesticides, names of preparative forms and active substances of pesticides.

Classification of pesticides by
chemical composition
Phosphorus-organic
Pyrethroid
Triazine
Chlorine organic
Benzimdazol

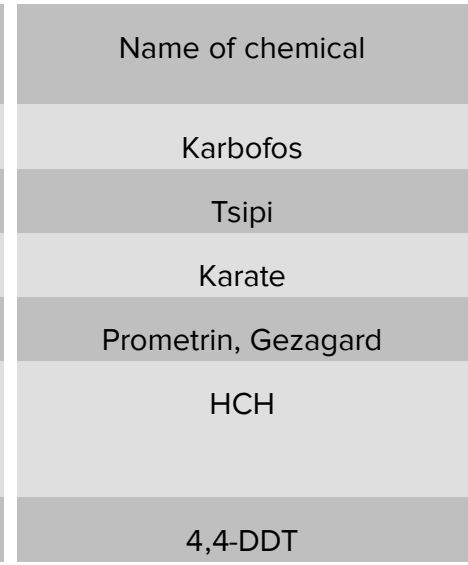

Active ingredient of chemical
Malathion
Cypermethrin
Lambda cyhalothrin
prometryn
Hexachlorocyclohexane
Dichlorodiphenyl-
trichloromethylmethane
Fundazole

the identification of these enzymes in microorganisms indicates the destructive potential of the culture.

A $5 \%$ aqueous solution of 2,3,5-triphenyltetrazolium chloride (TTC) was used to detect dehydrogenase activity in bacteria [12], which was added to M9 medium (composition in g: $\mathrm{Na}_{2} \mathrm{HPO}_{4}-6.0 ; \mathrm{KH} 2 \mathrm{PO} 4-3.0 ; \mathrm{NaCl}--0.5 ; \mathrm{NH} 4 \mathrm{Cl}$-- 1.0; distilled water 1000 $\mathrm{ml}, 2 \%$ of starvation agar) in the amount of $1 \%$ of the volume of the medium. The ability of microorganisms to destroy the drug testified staining of colonies and the environment around them in red, indicating the formation of reduced triphenylformazan (TPF). After incubation period in thermostat, the presence or absence of microbial growth, stained colonies were noted. A change in colony coloration indicated the use of carbon from the substrate by microorganisms. The use of carbon contained in pesticide by various microbial strains indicated the possibility of its decomposition.

The macerating ability determination was carried out according to Johnson. $10 \mathrm{ml}$ of sterile potato broth was sown with the culture of the studied bacteria and kept for ten days in thermostat at the temperature of $28^{\circ} \mathrm{C}$. Then the culture fluid was poured into a 20--30 $\mathrm{ml}$ cup and thin slices of potatoes, beets, and carrots were put into it. The tissue maceration was determined at $40{ }^{\circ} \mathrm{C}$. The degree of softening of the slice on tubers and root crops was checked with a fine needle at regular intervals for 6 hours. If the slice was softened, this indicated the presence of protopectinase in the culture fluid. The maceration or the decay of the tissue of higher plants into individual cells occurs under the action of pectolytic enzymes that destroy pectin in the middle plate [13].

To identify the cellulolytic activity, the strain of microorganisms was seeded with the help of a loop "medallions" (5--8 mm in diameter) on the surface of Glucose Salts Agar containing $0.2 \%$ of soluble cellulose (carboxymethylcellulose), then incubated for 48 hours at $28{ }^{\circ} \mathrm{C}$. After this, the cups were poured with a $0.1 \%$ aqueous solution of Congo 
red $(4 \mathrm{ml})$ and kept for 20 minutes. The dye was decanted, the cups were washed with $8 \%$ aqueous $\mathrm{NaCl}$ solution [14].

The study used positive and negative controls:

- positive control is a strain from the collection of Bacillus simplex 422 (received from aphids), which has pronounced cellulolytic activity.

- negative control is sterile tap water without microorganism.

The result records were conducted visually. The presence of bright, unstained zones in the areas of bacterial growth or around medallions was considered a positive reaction (indicating the production of cellulolytic enzymes). A negative reaction was considered the absence of bright unstained zones in the places of bacterial growth and around the medallions.

The study of the effect of a destructor microorganism on germination was carried out using seeds of a monocot (wheat) and dicotyledonous (carrot) plants. For the study the intact, leveled by the size seeds of one reproduction year with good germination ( $\geq 90 \%$ ) were used. Before soaking, the seeds were disinfected with $1 \%$ potassium permanganate solution for 10 minutes. Then they were placed into the sterile Petri dishes on filter paper 100 pieces each and poured the required amount of distilled water (control) and suspensions of the studied bacteria (experiment). The experiment was carried out in three replications at the temperature of $24{ }^{\circ} \mathrm{C}$. For 7 days, both germination and viability of seedlings had been carefully monitored. The germination was determined on day 10 by the formula adjusted for germination in control:

$$
A=B / C \cdot 100 \% \text {, }
$$

where $B$ is the number of seeds germinated in the experiment; $C$ is the number of seeds germinated in the control [15].

Fibrinolysin, hemolysin and arginine dehydrolase have been studied as enzymes responsible for the invasiveness of bacteria in animals and humans. Fibrinolysin was determined in a test tube with fibrin (a blood clot washed from red blood cells) where the test culture was applied. After the incubation, the result was taken into account. With a positive result, the clot had dissolved. Staphylococcus aureus was used as a test organism.

Hemolysins were determined by plating the test culture in a Petri dish with blood agar. The cups were incubated in a thermostat at $37^{\circ} \mathrm{C}$ during the day. With a positive reaction, the hemolysis zones are formed around the plaques. The Staphylococcus aureus was used as a test organism. 
The determination of arginine dehydrolase activity was studied on the medium of the following composition (g/l): enzyme peptone -- $1 \mathrm{~g} ; \mathrm{NaC1}$-- $5 \mathrm{~g}$; KHPO4 -- $0.3 \mathrm{~g} ; \mathrm{L}(+)$ arginine $\mathrm{HCl}--10 \mathrm{~g}$; phenol red -- $0.01 \mathrm{~g}$; agar-agar -- $15 \mathrm{~g}$; pH = 6.9--7.0. Microorganisms with arginine dehydrolase form $\mathrm{NH}_{3}$ from arginine under anaerobic conditions, which is accompanied by alkalization of the medium and a change in the indicator color. The medium was poured into $5 \mathrm{ml}$ sterile tubes and, after cooling, the test culture was inoculated with two test tubes, two of which were coated with sterile paraffine oil [14]. The results were taken into account after $24-48$ hours. In the case of a positive reaction in bacteria grown under anaerobic conditions, the color of the medium changes from yellow to red. As a test organism, the strain Pseudomonas fluorescens from the museum of the Department was used.

The determination of soil toxicity by biotesting using earthworms was carried out by the method of short-term biotesting (screening test) -- up to 2 days and long-term (chronic) -- up to 28--30 days. This method allows us to determine the acute and chronic toxic effects of soil on earthworms by their survival and behavioral responses. The survival indicator would be the percentage determination of the average number of test objects that survived in the test soil or in the control soil over a specific time. The criterion of toxicity would be the death of 50 percent or more of earthworms over 2 days in the test soil compared with the control one [16].

In our study, the individuals of the hybrid of California hybrid (Eisenia foetida) of the same age and size as well as weight characteristics, adapted for life in the created conditions were used. Test objects planted into the containers amounted to 20 individuals per $2 \mathrm{~kg}$ of substrate. High-moor peat added to the soil to feed the worms at the rate of $20 \%$ of the total soil mass $(\mathrm{pH}=8.3)$. The straw was added to aerate the soil. The resulting substrate was thoroughly mixed, then distributed in the prepared plastic containers. To control the prepared original soil was left unchanged, and as an experiment, a suspension of microorganisms of destructors in the amount of 108 cells per gram was added before introducing test vermiculture.

The statistical data processing was performed using the Excel integrated statistical package (MS Office 2007). All experiments were performed three times. 


\section{Results}

\subsection{Exploring the ability of a strain-destructor to use carbon pesti- cides}

Currently, the biological products based on microorganisms-destructors adapted to a specific type of pollutant are widely used. The most promising approach for remediation of contaminated soils is the use of biological products based on microorganismsdestructors with a broad spectrum of action. The composition of such biological products should include microorganisms from several types of destructors, or one, capable of destroying substances of different chemical composition.

While determining the dehydrogenase activity of strain-destructor of prometrin it was found out that this strain can also use the active ingredients of pesticides of malathion, $\mathrm{HCH}$ and 4,4-DDT as the only carbon source.

\subsection{Study of enzymes of pathogenicity}

The results of the study of the enzymatic activity of the strain-destructor are presented in Table 2.

The analysis of enzymatic activity of the strain in relation to plant tissues did not reveal neither macerating nor cellulolytic activities. The study of pathogenicity factors in animals and humans did not show the presence of arginine dehydrolase, fibrinolysin and hemolysin. Consequently, the strain-destructor is not pathogenic in relation to plants, animals, and humans.

TABLE 2: Pathogenicity factors of strain-destructor Pseudomonas putida P2.

Pathogenicity factor
Maceration
Cellulolytic activity
Formation of NH3 from arginine
Dissolution of fibrin
Red blood cell destruction

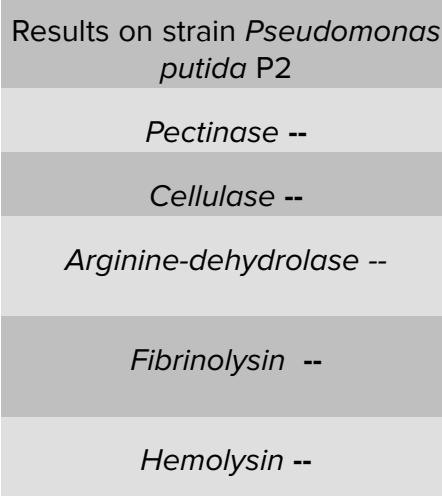

Microorganism test result

Pectinase + Bacillus simplex 422

Cellulase + Bacillus simplex 422

Arginine-dehydrolase + Pseudomonas fluorescens

Fibrinolysin + Staphylococcus aureus

Hemolysin -- Staphylococcus aureus 


\subsection{The effect of destructor microorganism on seed germination}

The studies allowed learning about the effect of strain Pseudomonas putida P2 on the seeds of wheat of the variety Saratovskaya 70 and carrots of the variety Samson for 10 days. The results obtained are presented in Table 3.

TABLE 3: The effect of strain Pseudomonas putida P2 on germination of seeds of wheat variety Saratovskaya 70 and carrots variety Samson.

Seed test
Wheat
Carrot

Germination, \% (control)
96
95

Germination, \% (test)
98
96

It was shown that the strain under study had no negative effect on germination; on the contrary, it stimulated seed germination. Thus, during the test with the wheat seeds, the germination was $98 \%$, which was $2 \%$ higher compared to the control values, and with the carrot seeds, germination was $96 \%$, which was $1 \%$ higher compared to the control values. Thus, the studied strain increases the germination of wheat seeds of Saratovskaya 70 variety and Samson carrots.

\subsection{The toxicity of the strain Pseudomonas putida P2 determina- tion using earthworms}

The criterion of toxicity is the absence of such phenomenon as earthworms bury into tested soil, active crawling on the surface of the earth and attempts to crawl out of the box (avoidance test). Due to some ecological and physiological features the earthworms are in contact with soil particles, air and moisture, not only on the surface of the skin, but also inside the digestive tract. Processing a large amount of soil, they are exposed to the direct influence of inorganic and organic substances in the soil. The results are presented in Table 4.

TABLE 4: Determination of toxicity of strain Pseudomonas putida P2 using earthworms.

Types of experiments
Control (soil free from
destructor)
Test (soil with destructor)

\begin{tabular}{c|c}
\multicolumn{2}{|c}{ Number of alive specimen, \% } \\
$\begin{array}{c}3 \text { days after mixture's } \\
\text { introduction into soil }\end{array}$ & $\begin{array}{c}30 \text { days after mixture's } \\
\text { introduction into soil }\end{array}$ \\
\hline 99 & 91.2 \\
\hline 99 & 89.9 \\
\hline
\end{tabular}

The biotesting of Pseudomonas putida P2 strain on the earthworms revealed no acute toxicity of the culture. It was found out that the mortality of Eisenia foetida on 
the $3^{r d}$ day of experiment did not exceed $1 \%$ neither in the control nor in the samples with the destructor. By the $30^{\text {th }}$ day a stably increasing dynamics of the death rate of worms in the samples with the destructor up to $10.1 \%$ was observed, and up to $8.8 \%$ without it. The increase in mortality in all samples may be the cause of natural decline of worms cultivated in the laboratory. The results of the $30^{\text {th }}$ day also indicated the absence of moderately-lethal effects in earthworms by the end of the experiment and the absence of any effect of the destructor on test objects indicators (when compared with the control values). Observing the behavior of lumbricide, we have not identified any negative behavioral reactions.

The analysis of data obtained from model pollution showed that the introduction of the destructor of prometrin Pseudomonas putida P2 into the soil can create favorable conditions for the vital activity and reproduction of earthworms.

\section{Conclusion}

The determination of dehydrogenase activity of strain-destructor of prometrin showed that this strain can also use the active ingredients of pesticides, i.e. malathion, $\mathrm{HCH}$ and 4,4-DDT as the only carbon source. It was also stated that the studied strain Pseudomonas putida P2 increases the germination of seeds of the variety Saratovskaya 70 and carrots of the variety Samson and does not possess pathogenic factors for plants and animals. The biotesting of the strain on earthworms revealed no acute toxicity of the culture. The data obtained from the model pollution showed that the introduction of the destructor of prometrin Pseudomonas putida P2 into the soil can create favorable conditions for both vital activity and reproduction of earthworms. Based on the results obtained, this strain can be recommended for the creation of a biological product intended for the bioremediation of lands contaminated with pesticides.

\section{References}

[1] Turkovskaya, O.V., Panchenko, L.V., Dubrovskaya E.V. et al. (2003). Biotechnology for environmental cleanup. Coll. scientific works "High Technologies -- Path to Progress". Saratov: Scientific Book, pp. 76--81.

[2] Gorbatenko, N.O. (2006). Pesticides: structure and degradation processes. Successes of Biological Chemistry, vol. 4, pp. 323--348.

[3] Turkovskaya, O.V., Dubrovskaya, E.V., Muratova A.Yu. et al. (2002). Possibilities of modern methods of environmental bioremediation. Proceedings of the 1st 
International Congress "Biotechnology -- state and development prospects", p. 290. Moscow.

[4] Ivlev, A.M., Derbentseva, A.M. (2003). Soil degradation and their recultivation. Vladivostok: FESU Publishing House, 86 p.

[5] Pleshakova, E.V. (2010). Ecological and functional aspects of microbial remediation of oil-contaminated soils. PhD dissertation thesis. Saratov, $42 \mathrm{p}$.

[6] Koshelev, A.V., Golovkov, V.F., Tikhomirova, E.I., Ksenofontova, O. Yu. (2017). Questions of modern science and practice. University named after V.I. Vernadsky, no. 3(65). DOI 10.17277/voprosy.217.03. pp. 040--050

[7] Reshetov, G.G., Belov, V.S., Korsak, V.V. (2008). Soils of Saratov region. Saratov: Saratov State Social and Economic University, 180 p.

[8] Kolesnikov, S.I., Kaseev, K.Sh., Valkov, V.F. (2006). Ecological state and functions of soils in the conditions of chemical pollution. Rostov-on-Don: Rostizdat, 385 p.

[9] Oliskevich, V.V., Talalovskaya, N.M., Tikhomirova, E.I., Ksenofontova, O.Yu., Tretyakova, S.E. (2018). The experience of creating biological products based on biodestructors of pesticides and testing their effectiveness on experimentally contaminated soil systems. Materials of IV Intern. conf. "Actual scientific and scientific and technical problems of ensuring chemical safety", p. 110. Moscow: Publishing House of the Russian Academy of Sciences.

[10] Korolev, V.A. (2001). Cleaning soils from pollution. Moscow: Agro, 365 p.

[11] Ksenofontova, O.Yu., Tretyakov, S.E., Tikhomirova, E.I., Vasnetsov, E.V. (2016). Technology development for the use of biological product for the remediation of soils contaminated with pesticide prometrin in laboratory and field conditions. Proceedings of Samara Scientific Center of the Russian Academy of Sciences, vol. 18, no. 2--3, pp. 718--723.

[12] Granatskaya, T.A., Dvornikova, T.P. (1996). Method for detection of xenobiotic destructive microorganisms Pat. no. 2051961, Russian Federation, IPC, Section C C12 C12Q C12Q 1/00 Measurement or testing using enzymes or microorganisms; formulations; methods of obtaining such compositions. Date of patent publication: 01.10.1996.

[13] Zheldakova, R.A., Myamin, V.E. (2006). Phytopathogenic microorganisms. Study guide for students of Biology Department. Minsk: BSU, 116 p.

[14] Netrusov A.I. et al. (2005). Case study on Microbiology. Study Book for HEl students. Moscow: Publishing Center Academy, 608 p.

[15] GOST 12038-84. (2011). Crop seeds. Methods for determining germination. Moscow: Standardinform, $30 \mathrm{p}$. 
[16] International Standard ISO 11268-1 Determination of pollution from acute lethal toxicity in earthworms. 